\title{
Biology of the Impaired Endothelium
}

\author{
Elizabeth G. Nabel, MD
}

\begin{abstract}
The endothelium is a regulatory organ that mediates hemostasis, contractility, cellular proliferation, and inflammatory mechanisms in the vessel wall. Injury to the endothelium from hypertension, smoking, hyperlipidemia, and diabetes mellitus disrupts normal regulatory properties and results in abnormal endothelial cell function. Clinically, endothelial cell dysfunction can be manifested as vasospasm, thrombus formation, atherosclerosis, or restenosis. The normal hemostatic properties of the endothelium include the maintenance of a nonadhesive luminal surface, antithrombotic properties, anticoagulant properties, and fibrinolytic properties. The endothellal cell regulates smooth muscle cell contractility by the production of relaxing and constricting factors in response to physiologic stimuli. Endothelial cell injury is also an initial event in the development of atheroscicrosis and restenosis by facilitating platelet adhesion and aggregation and by signaling the release of mitogens from platelets, macrophages, and endothelial cells, which stimulate smooth muscle cell proliferation. In addition, endothelial cells undergo morphologic and functional alterations in response to cytokine signals, which may contribute to the pathogenesis of vasculitis and atherosclerosis. In sum, the normal endothelium performs many regulatory functions which become altered when the endothelium is injured.
\end{abstract}

(Am J Cardiol 1991;68:6C-8C)

From the Department of Medicine, University of Michigan School of Medicine, Ann Arbor, Michigan.

Address for reprints: Elizabeth G. Nabel, MD, Department of Medicine, University of Michigan Medical Center, 1150 W. Medical Center Drive, MSRBII, Room 3560, Ann Arbor, Michigan 48109-0688.
$\Gamma$ The normal endothelium maintains a nonadhesive luminal surface and has fibrinolytic, anticoagulant, and antithrombotic properties [1,2]. A normal endothelial surface prevents the attachment of platelets. Platelet aggregation and adhesion are also normally inhibited by endothelial cell synthesis of prostacyclin (prostaglandin $I_{2}$ ) and endothelium-derived relaxing factor (EDRF) [3,4]. Antithrombotic and fibrinolytic properties of the endothelium are regulated by basal synthesis of tissue-type plasminogen activator (t-PA), which stimulates lysis of fibrin clots. Antithrombotic properties in the vessel wall are regulated through synthesis of antithrombin III, which binds to and inactivates thrombin, factor $\mathrm{X}$, and other serine proteases [5]. Anticoagulant properties in the vessel wall are regulated by several pathways. The principal anticoagulant action of the endothelium is mediated through protein $\mathrm{C}$ and protein $S$ [6]. The binding of thrombin to thrombomodulin serves to activate protein $C$; the latter, in turn, blocks factors Va and VIIIa. Antithrombin III inactivates thrombin and factor $\mathrm{Xa}$, as well as endothelial cell serine proteases. The thrombin-thrombomodulin complex inactivates the procoagulant properties of thrombin, such as platelet activation. In addition, endothclial ccll production of heparin-like glycosaminoglycans catalyzes the inactivation of coagulation proteases such as thrombin and factor $X[7]$.

\section{HEMOSTASIS}

Normal hemostasis is disrupted when the vessel is injured. Subendothelial (collagen matrix) basement membrane is exposed. von Willebrand's factor is activated by thrombin to facilitate platelet adhesion and aggregation. Platelet-activating factor also contributes to primary hemostasis. Endogenous thrombolysis (t-PA) is inhibited by plasminogen activalur inhibitor. Endolhelial cell disruption also exposes tissue factor VII, which activates the extrinsic coagulation pathway, as well as factor XII, which stimulates the intrinsic coagulation pathway. Endothelial cell serine proteases also facilitate thrombus formation.

Endothelial cell injury stimulates primary hemo- 
stasis by several mechanisms. Platelet adhesion occurs when platelets bind to the subendothelium via the platelet collagen receptor glycoprotein IA and to basement membrane by interactions with von Willebrand's factor and the glycoprotein IB receptor. Platelet aggregation follows when platelets bind to other platelets via the platelet glycoprotein receptor IIB IIIA. Platelet degranulation results in the release of vasoactive proteins from $\alpha$ granules, such as adenosine diphosphate (ADP), serotonin, thromboxane $A_{2}$, thrombin, and histamine, which further promote platelet aggregation, vasoconstriction, leukocyte chemostasis, and formation of a hemostatic plug.

\section{CONTRACTIUTY}

The healthy endothelium regulates vascular contractility and promotes vascular relaxation. The endothelium contains receptors for various pharmacologic stimuli, including thrombin, vasopressin, acetylcholine, and platelet granulation products [8]. Receptor binding stimulates endothelial cell synthesis and release of EDRF, which acts locally on smooth muscle cells to stimulate production of cyclic guanosine monophosphate (cGMP) which, in turn, mediates relaxation [9]. Although more investigation is needed, there is convincing evidence that EDRF encompasses a group of substances, one of which is probably nitrous oxide $[9,10]$. Other non-receptor-mediated stimuli, such as shear stress and calcium ionophore, also initiate EDRF release [11]. Endothelial cells promote smooth muscle cell relaxation through the local production of prostacyclin which causes an increase in cyclic adenosine monophosphate (cAMP), resulting in vasodilation.

These vasodilator mechanisms are counterbalanced by vasoconstrictor substances produced by the endothelium. For example, endothelin is a potent vasoconstrictor produced by the endothelial cells in response to hypoxia and other stimuli [12]. The exact physiologic role of endothelin in normal and atherosclerotic conditions is now under evaluation.

A complex series of events occurs when the endothelium is injured. Since receptor-mediated stimulation of EDRF is disrupted, physiologic and pharmacologic stimuli produce a direct effect on smooth muscle cells, resulting in vasoconstriction. For example, vasoconstriction is routinely observed following coronary angioplasty [13]. Vasospasm surrounding an atherosclerotic plaque may occur due to deficient release of EDRF, and probably accounts for some angina experienced by patients with coronary artery disease.

\section{CELLULAR PROLIFERATION}

Injury to the endothelium may initiate the development of atherosclerosis [14]. Circulating monocytes adhere to the injured vessel surface and migrate into the intima, take up extracellular lipid as macrophages, and develop into foam cells. Growth factors, released by platelets, endothelial cells, and macrophages, promote smooth muscle cell migration into the intima and proliferation. Macrophages and proliferating smooth muscle cells engage in collagen matrix synthesis. Abnormal cellular proliferation, in combination with calcium deposition and thrombus formation, results in the development of an atherosclerotic plaque. Balloon injury following angioplasty initiates a similar process of pathologic cellular proliferation, which bccomes manifest over scveral months as restcnosis [15]. Release of mitogens by activated endothelium, platelets, and mononuclear cells may be associated with a change in medial smooth muscle cells. The smooth muscle cell is normally refractory to growth factors and does not synthesize collagen matrix. When the blood vessel is injured, the smooth muscle cell may undergo a 'phenotypic' change to a synthetic cell where it becomes noncontractile, responsive to growth factors, and capable of connective tissue synthesis [16].

\section{IMMUNITY AND INFLAMMATION}

The endothelium is responsive to a number of cytokines, including the interferons $(\alpha, \beta$, and $\lambda)$, tumor necrosis factor- $\alpha$, interleukin-1, and interleukin-6 [17]. These products of the immune system can induce changes in endothelial cell structure and function by a process termed endothelial activation. Endothelial cells become activated by the binding of leukocytes, monocytes, and lymphocytes to the endothelium by adhesion molecules. For example, interleukin-1 can induce the synthesis of endothelial leukocyte adhesion molecule-1 (ELAM-1), which stimulates neutrophil adhesion to endothelial cells [18]. Interferon- $\lambda$ stimulates intracellular adhesion molecule 1 (ICAM-1) expression, which in turn promotes lymphocyte attachment and a local immune response. The adhesion of mononuclear cells to endothelial cells by adhesion molecules is a process that is central to vascular inflammation and a response to immune injury $[19,20]$. These mechanisms may also be responsible, in part, for the accelerated atherosclerosis observed in cardiac transplant arteries. 
In conclusion, the endothelium is a highly active and reactive tissue that regulates hemostasis, vascular contractility, cellular proliferation, and immu nity and inflammation. As our understanding of the endothclium expands, new therapeutic modalities are likely to emerge, based on recombinant DNA technology $[21,22]$.

\section{REFERENCES}

1 Esmon CT. The regulation of natural anticoagulant pathways. Science 1987;235: $1348-1352$.

2. Rodgers GM. Hemostatic properties of normal and perturbed vascular cells. FASEBJ 1988;2:116-123.

3. Moncada S. Prostacyclin and arterial wall biology. Atteriosclerosis 1982;2:193207.

4. Radomski MW, Palmer RMJ, Moncada S. Endogenous nitric oxide inhibits human platelet adhesion to vascular endothelium. Lancet 1987;ii:1057-1058.

5. Rosenberg RD, Rosenberg JS. Natural anticoagulant mechanisms. J Clin Irvest 1984;74:1-6.

6. Stern D, Brett J, Harris K, Nawroth P. Participation of endothelial cells in the protein $C$-protein $S$ anticoagulant pathway: the synthesis and release of protein $S$. JCell Biol 1986;102:1971-1978.

7. Ofosu FA, Modi GJ, Smith LM, Cerskus AL, Hirsh J, Blajchman MA. Heparan sulfate and dermatan sulfate inhibit the generation of thrombin activity in plasma by complementary pathways. Blood 1984;64:742-747.

8. Vanhoutte PM, Rubanyi GM, Miller VM, Houston DS. Modulation of vascular smooth muscle contraction by the endothelium. Ann Rev Physiol 1986;48: 373-376.

9. Palmer RMJ, Ferrige AG, Moncada S. Nitric oxide release accounts for the biological activity of endothelium-derived relaxing factor. Nature 1987;327:524526.

10. Ignarro LJ, Harbison RG, Wood SK, Kadowitz PJ. Activation of purified soluble guanylate cyclase by endothelium-derived relaxing factor from intrapulmo- nary artery and vein: Stimulation of acetylcholine, bradykinin and arachidonic acid. IPharmacol Exp Ther 1986;237:893-900.

11. Holtz J, Forstermann U, Pohl U, Giesler M, Bassenge E. Flow-dependent, endothelium-mediated dilation of epicardial coronary arteries in conscious dogs: effects of cyclooxygenase inhibition. J Cardiovasc Pharmacol 1984;6:1161-1169.

12. Yanagisawa $M$, Kurihara $H$, Kimura $S$, Tomobe $Y$, Kobayashi $M$, Mitsui $Y$, Yazaki Y, Goto K, Masaki T. A novel potent vasoconstrictor peptide produced by vascular endothelial cells. Nature 1988;332:411-415.

13. Fischell TA, Bausback KN, McDonald TV. Evidence for altered epicardial coronary artery autoregulation as a cause of distal coronary vasoconstriction after successful percutaneous transluminal coronary angioplasty. J Clin Invest 1990;86: $575-584$.

14. Ross R. The pathogenesis of atherosclerosis-an update. $N$ Engl $J$ Med 1986;314:488-500.

15. McBride W, Lange RA, Hillis LD. Restenosis after successful coronary angioplasty-pathophysiology and prevention. N Engl J Med 1988;318:1734-1737. 16. Ross $R$. The pathogenesis of atherosclerosis. In: Heart Disease, A Textbook of Cardiovascular Medicine, Braunwald E (ed). Philadelphia, PA: W.B. Saunders, 1988:1135-1152.

17. Munro JM, Cotran RS. The pathogenesis of atherosclerosis: atherogenesis and inflammation. Lab Invest 1988;58:249-261.

18. Bevilacqua MP, Pober JS, Wheeler ME, Cotran RS, Gimbrone MA. Interleukin-1 acts on cultured human vascular endothelium to increase the adhesion of polymorphonuclear leukocytes, monocytes, and related leukocyte cell lines. I Clin Invest 1985;76:2003-2011.

19. Collins T, Lapierre LA, Fiers W, Strominger JL, Pober JS. Recombinant human tumor necrosis factor increases mRNA levels and surface expression of HLA-A,B antigens in vascular endothelial cells and dermal fibroblasts in vitro. Proc Natl Acad Sci USA 1986;83:446-450.

20. Dustin ML, Rothlein $R$, Bhan $A K$, Dinarello CA. Induction by Il-1 and interferon-gamma; tissue distribution, biochemistry, and function of a natural adherence molecule (ILAM-1).JImmun 1986;137:245-254.

21 Nabel EG, Plautz G, Boyce FM, Stanley JC, Nabel GJ. Recombinant gene expression in vivowithin endothelial cells of the ar terial wall. Scierce 1989;244:1324 1325.

22. Nabel EG, Plautz G, Nabel GJ. Site-specific gene expression in vivo by direct gene transfer into the arlerial wall. Scierwe 1990;249:1285-1288. 